\title{
The importance of clinical and translational research for West Virginia
}

Uma Sundaram MD ${ }^{1}$

Author Affiliations:

1. Marshall University Joan C. Edwards School of Medicine, Huntington, West Virginia

The author has no financial disclosures to declare and no conflicts of interest to report.

Corresponding Author:

Uma Sundaram MD

Vice Dean for Research \& Graduate Education

Marshall Universtiy Joan C. Edwards School of Medicine

Huntington, West Virginia

Email: bailey332@marshall.edu 


\section{Keywords}

research, clinical and translational research, Appalachia

\section{Clinical and Translational Science Research}

The National Center for Advancing Translational Sciences defines clinical and translational science research (CTSR) as "the process of turning observations in the laboratory, clinic and community into interventions that improve the health of individuals and the public - from diagnostics and therapeutics to medical procedures and behavioral changes." Exactly where anyone's current research is in the translational science spectrum is defined by the T0 to T4 classification system where T0 Research is basic biomedical research, T1 Research is translation to humans, T2 Research is translation to patients, T3 Research is translation to clinical practice and T4 Research is translation to communities. ${ }^{1}$

This drive to transform classic basic biomedical or "bench" research to that which is relevant to patients and the communities they reside in arose as a result of increasing concern that basic scientific breakthrough discoveries do not result in widespread breakthroughs in patient care. In support of this concern was a study by JP Ioannidis and co-workers ${ }^{2}$ which found that out of 25,290 articles in top basic science journals published between 1979-1983, two decades later, only one of them had a major impact on current medical practice! In order to respond to this dramatic disconnect the biomedical research climate and culture required transformation in order to meet the public's expectation that public funding for research had to have a direct impact on improving human health and disease treatment. Thus, to promote patient centric research that is relevant to the community, the National Institutes of Health $(\mathrm{NIH})$ created the National Center for Advancing Translational Sciences (NCATS) and began the multi-million dollar Clinical and Translational Science Awards (CTSA) in 2006 and fully implemented them in 2012, comprising of some 60 grantee institutions and their partners. ${ }^{3}$ Marshall University's Appalachian Clinical and Translational Science Institute (ACTSI; https://jcesom.marshall.edu/research/actsi) in partnership with University of Kentucky is supported by this CTSA program. The paradigm shift by the NIH emphasizing patient based research which results in improvement of the health of the community is both necessary and ideal for West Virginia with its many health care disparities.

\section{Significance of clinical and translational research for West Virginia}

West Virginia (WV) is the only state that is entirely within historically and geographically defined Appalachia. The population of Appalachia is ethnically quite homogenous and has a rich cultural tradition. However, Appalachians in WV are generally characterized by poor health outcomes, poverty (4th lowest household income), socioeconomic challenges, and very rural geography, with $93 \%$ of counties designated as Heath Care Professional Shortage Areas and/or Medically Underserved Areas. ${ }^{5,6}$ In Central Appalachia (CA) Eastern Kentucky and southeastern Ohio have similar characteristics to $\mathrm{WV}{ }^{7}$ The primary healthcare disparity phenotype of this population is obesity. ${ }^{4}$ The obesity associated morbidities are overwhelming in WV and eastern KY ${ }^{4,7}$ Obesity associated morbidities such diabetes, heart disease, heart attack, high blood pressure, stroke, and cancer are among the highest, if not the highest, in the country. ${ }^{4,7,8}$ In just the past two years, most recent data for WV indicates the state has dropped from 44th to tie for 49th, indicating the worsening prevalence of obesity and related conditions. ${ }^{9}$ 
Along with obesity, WV/CA ranks first in the nation for hypertension, with a current adult hypertensive rate of $42.7 \%$ (increased from a rate of $41 \%$ in past year) in adults. ${ }^{9}$ Further, mortality for obesity related diseases is equally prevalent with heart disease, the second leading cause of death, occurring at a rate of 251.8 per 1,000 deaths in $\mathrm{WV}$, as compared to the U.S. rate of 193 per 1,000 deaths. ${ }^{10}$ Cancers are the leading cause of death, occurring at a rate of 254.2 per 1,000 in WV compared to the U.S. rate of 184.7 per $1,000 .{ }^{10}$ In addition, deaths due to stroke occur at a rate of 53.2 per 1,000 as compared to 40.7 for the U.S., deaths due to diabetes at a rate of 45.3 per 1,000 compared to the U.S. rate of 23.9, and deaths due to renal disease at a rate of 24.2 per 1,000 in West Virginia, as compared to the U.S. rate of 14.9 per $1,000 .{ }^{10}$ All of these obesity related diseases are expected to increase significantly over the next ten to fifteen years. ${ }^{4}$

Clearly West Virginia and surrounding Central Appalachia have enormous health care disparities. In order to creatively address these many health care concerns, it is essential to better understand them as well as come up with novel solutions to address them. In turn both of these desired outcomes require the research to span the spectrum of translational research from T0 to $\mathrm{T} 4$ - clinically relevant biomedical research that can be translated to patient centric research that will positively impart the health of the community as a whole. Clinical and translational research that is relevant to West Virginia and Central Appalachia is not only important for this region, but to all other rural areas of the United States as they also suffer from similar health care disparities. Additionally, given the poor economic conditions of this region, our patients lack the resources to seek state of the art health care elsewhere, but clinical and translational research locally will bring the latest and greatest in health care to our patients here in West Virginia. Finally, as health care professionals, it is not enough for us to do more of the same for our patients, but to do better and clinical and translational research will allow us to do just that for West Virginians. 


\section{References}

1. University of Wisconsin Institute for Clinical and Translational Research. https://ictr.wisc.edu/what-are-the-t0to-t4-research-classifications.

2. Ioannidis JP. Materializing research promises: opportunities, priorities and conflicts in translational medicine. J Transl Med. Published online. 2004 Jan 31. doi: 10.1186/1479-5876-2-5.

3. National Institutes of Health. Sep 17, 2009. Re-engineering the Clinical Research Enterprise: Translational Research. Retrieved June 18, 2010.

4. Trust for America's Health. 2016. The state of obesity in West Virginia. Retrieved from http://stateofobesity.org/states/wv/.

5. U.S. Census. 2016. State median income. Retrieved from https://www.census.gov/hhes/www/income/data/statemedian/.

6. Health Resources and Services Administration. 2016. West Virginia MUA results. Retrieved from http://datawarehouse.hrsa.gov/tools/analyzers/MuaSearchResults.aspx.

7. Trust for America's Heath. 2016.The state of obesity in Kentucky. Retrieved from http://stateofobesity.org/states/oh/.

8. United Health Foundation. 2015. America's annual health rankings: Annual report. Retrieved from Http://cdnfiles.americashealthrankings.org/SiteFiles/Reports/2015AHR_Annual-v1.pdf

9. Trust for America's Health. 2016. Adult obesity in the United States. Retrieved from http://stateofobesity.org/adult-obesity/

10. West Virginia Health Statistics Center. 2016. West Virginia vital statistics 2013. Retrieved from http://www.wvdhhr.org/bph/hsc/pubs/vital/2013/2013Vital.pdf 